\title{
Concentration of 18:1 and 16:1 transunsaturated fatty acids in the adipose body tissue of decedents dying of ischaemic heart disease compared with controls: analysis by gas liquid chromatography
}

\author{
LEO H THOMAS, J A WINTER, AND R G SCOTT \\ From the Departments of Science and Mathematics/Computer Science, The Polytechnic of Wales, Pontypridd, \\ Mid-Glamorgan CF37 1DL, UK
}

\begin{abstract}
SUMMARY Proportions of "lower" $16: 1$ and 18:1 trans acids $\left(T_{L}\right)$ and "higher" $C_{20}$ and $C_{22}$ trans acids $\left(\mathrm{T}_{\mathrm{H}}\right)$ in samples of depot fat taken at postmortem examination from 136 people who had died of ischaemic heart disease (cases) and from those who had died of unrelated causes (controls) have been determined. Whereas mean percentages of $T_{H}$ are virtually identical for cases and controls, the mean value of $T_{L}$ was significantly higher for the case specimens. Although these lower trans acids are present in small amounts in ruminant-animal fat, they are more characteristic of commercially hydrogenated fats. We conclude, therefore, that the cases consumed on average a higher proportion of those hydrogenated fats rich in 16:1 trans and 18:1 trans acids and a lower proportion of ruminant fat than did the controls.
\end{abstract}

We have previously shown ${ }^{1-3}$ that samples of body fat taken from people who had died of ischaemic heart disease (cases) when compared with controls who had died of other causes had lower mean values of certain odd-number and branched-chain acids (L) characteristic of ruminant-animal fat and higher mean values of total transunsaturated fatty acids $(T)$. There was no difference in the mean values of certain "higher ( $\mathrm{C}_{20}$ and $\mathrm{C}_{22}$ mostly monoenoic) acids" $(\mathrm{H})$. The ratio $\mathrm{T} / \mathrm{L}$ was significantly higher in the cases than the controls and increased linearly with increases in $\mathrm{H}$ in both cases and controls.

We assumed that the similar mean values of $\mathrm{H}$ implied that the mean values of "higher trans acids" $\left(T_{H}\right)$ would be similar and that these higher trans acids were not a hazard. Consequently, we were driven to the hypothesis that the observed differences in $\mathrm{T}$ and in $\mathrm{T} / \mathrm{L}$ were due to a difference in "lower trans acids" $\left(T_{L}\right)$-that is, in 18:1 and 16:1 trans acids-and that any risk attached preferentially to $T_{L}$.

We can now report on direct measurements of $T_{L}$ by gas-liquid chromatography using a more recently developed highly polar liquid phase.

\section{Methods}

The methyl esters were those used previously ${ }^{1}$ that were derived from adipose tissue specimens collected over the period 1976-8. The methyl esters (ca 100 $\mathrm{mg}$ per sample) were stored in $\mathrm{CS}_{2}$ solution in sealed containers at $-20^{\circ} \mathrm{C}$ in the presence of tertbutyl hydroquinone antioxidant. Remeasurement of properties ( $T$ by infrared spectroscopy, GLC on EGSS-Y polyester) of several samples showed no evidence of chemical change over this period. As an added precaution, the new GLC analyses were conducted in batches, each area at a time, in the order in which the specimens were originally received. Chromatograms were read by laboratory personnel with no knowledge of which samples were cases and which controls.

Fatty-acid compositions were determined with a Perkin-Elmer Model F17 gas chromatograph fitted with dual flame ionisation detectors. The columns were of stainless steel, $40 \mathrm{ft}$ by $1 / 8$ in diameter, packed with $20 \%$ OV-275 (Supelco Inc) coated on 100/120 mesh acid-washed and silanised chromosorb P. ${ }^{4}$ To eliminate baseline drift all measurements were conducted isothermally using pairs of matched columns. The column temperature was $220^{\circ} \mathrm{C}$; carrier gas, $\mathrm{N}_{2}$, flow rate $30 \mathrm{ml} / \mathrm{min}$; optimum ester loading $2 \mu \mathrm{l}$ of $\mathrm{CS}_{2}$ solution $(13 \mathrm{mg} / \mathrm{ml})$. Under such conditions, the retention time of $18: 1$ cis was 60 minutes from the solvent peak. 
Slight adjustments in carrier-gas flow were periodically made to keep the retention time of this major peak within narrow limits. Column performance was monitored by periodic analysis of a standard mixture of the methyl esters.

We analysed seven brands of butter and all exhibited five distinct peaks between 16:0 and 18:0 which we identified as follows:

(a) An amount of authentic 17:0 anteisomethyl ester was added to a sample of butter fat esters and the mixture injected on the column; that peak whose area increased relative to others was taken to be 17:0 anteiso. A similar procedure was adopted for other methyl esters.

(b) By determination of equivalent chain lengths $(E C L)^{5}{ }^{6}$ compared with published values.

We thereby identified the five peaks as:

Peak 1 17:0 iso, ECL $=16.40$

Peak 2 16:1 trans and 17:0 anteiso of identical $\mathrm{ECL}=16 \cdot 73$

Peak 3 17:0, ECL $=16.99$

Peak 4 16:1 cis, ECL $=17 \cdot 18$

Peak 5 17:1, ECL $=17 \cdot 44$

This was further confirmed by catalytic hydrogenation, ${ }^{7}$ which resulted in complete disappearance of peaks 4 and 5 and reduction in area of peak 2 by a factor on average ca $2 / 3$.

In those margarines containing hydrogenated marine oil and also in the adipose tissue specimens amounts of $16: 1$ cis substantially exceeded the amount present in butter fat. In such specimens the 16:1 cis peak broadened and included 17:0 and 17:1 as "shoulders." The ECL values of these components remained, however, such that the height of the peak was determined by 16:1 cis only. In specimens with the lowest values of $16: 1$ trans the baseline separation between peak 2 and the now adjacent large composite $16: 1$ cis peak was not always achieved. For this reason-and also for strict comparability with the previously derived values of total trans acids 1 -percentages 16:1 trans plus 17:0 anteiso were evaluated by measuring appropriate peak heights and retention times. ${ }^{8}$ We labelled the product of peak height and retention time for $16: 1$ cis as $x$ and that for the 16:1 trans plus 17:0 anteiso peak as $y$ which gives (\% 16:1 trans +\% 17:0 anteiso)/ (\% $16: 1 \mathrm{cis})=y / x$.

By rearrangement we get:

$\% 16: 1$ trans $=\mathrm{R}(\% 16: 1$ cis $+\% 16: 1$ trans $)$

$$
\begin{aligned}
& -(1-R)(\% 17: 0 \text { anteiso }) \\
= & R(\% 16: 1-(1-R)(\% 17: 0 \text { anteiso })
\end{aligned}
$$

in which $R=y /(x+y)$. To evaluate the percentage 16:1 trans from this equation, we used the percentage values of 16:1-combined cis and trans isomers-as previously obtained ${ }^{1}$ by use of a EGSS-Y column for 124 specimens ( 75 cases, 49 controls).

For the remaining 107 specimens (61 cases, 46 controls) the EGSS-Y column failed to separate completely $16: 1$ from the $17 \cdot 0$ branched-chain acids (iso plus anteiso), the column giving only the value of 16:1 and 17:0 br combined. It is easy, however, to show that we may now write:

\% 16:1 trans $=R(\% 16: 1+\% 17: 0$ br. $)-(\% 17: 0$ anteiso) - $\mathbf{R}(\%$ 17:0 iso)

in which combined percentages of $16: 1$ and $17: 0 \mathrm{br}$ were those previously obtained. ${ }^{1}$

Like the other odd-number and branched-chain components of $\mathrm{L}$, the branched-chain $\mathrm{C}_{17}$ acids in adipose samples derive essentially from ruminant-animal fat, and we found accordingly that in the 124 specimens ( 75 cases, 49 controls) the ratio 17:0 br/L was sensibly constant at $\mathbf{0} \cdot 22$ for both case and control samples. Furthermore, analysis of the seven butters previously mentioned showed that $60 \%$ of 17:0 br is 17:0 iso-a proportion that agrees well with that reported by Jensen et $a^{9}(61 \%)$. Equations 1 and 2 therefore finally become

$$
\begin{aligned}
& \text { \% } 16: 1 \text { trans }=R(\% 16: 1)-0.09(1-\mathrm{R}) \mathrm{L} \\
& \text { and } \\
& \% 16: 1 \text { trans }=\mathrm{R}(\% 16: 1+\% 17: 0 \mathrm{br}) \\
& -(0.09+0 \cdot 13 \mathrm{R}) \mathrm{L}
\end{aligned}
$$

Percentages 16:1 trans were then evaluated using (a) values of $\mathrm{R}$ obtained from the $\mathrm{OV}-275$ chromatograms and $(b)$ values of $16: 1, L$ and $16: 1+$ 17:0 br from EGSS-Y chromatograms as previously reported. It should be added that the magnitude of the term $0.09(1-R) L$ in equation 3 is small $(0.2$ on average) compared with that of $R(\% 16: 1), 0.9$ on average. Differences in \% 16:1 trans arise therefore mainly from differences in $R$ and 16:1 values. Likewise for equation 4 .

The 18:1 trans peak showed good but not complete base-line separation from the larger 18:1 cis peak. In view of the well-known difficulty of quantifying by area a smaller peak followed by a larger peak, percentages of 18:1 trans were evaluated from the heights and retention times of the 18:1 trans and 18:1 cis peaks using the combined 18:1 percentages previously measured ${ }^{1}$ on the EGSS-Y column.

\section{Results}

Table 1 records the mean of 18:1 trans, 16:1 trans, $T_{L}, L$, and $T_{L} / L$ for cases and controls in each area of the study. Cases have lower mean values of $L$ in nine of the 10 areas, higher values of $T_{L}$ in eight areas, and higher values of $T_{L} / L$ in nine areas. Individual values of $16: 1$ trans range from $0 \cdot 21 \%$ to $1 \cdot 55 \%, 18: 1$ trans 
from $0 \cdot 87 \%$ to $4 \cdot 35 \%$, and $T_{L}$ from $1 \cdot 21 \%$ to $5 \cdot 58 \%$. As expected-hydrogenated marine oil being the major source of trans acids-16:1 trans and 18:1 trans levels are clearly correlated.

The mean age at death of the cases was 52.7 and of the controls 51.5 years. We calculated the regression coefficients on age for 16:1 trans, 18:1 trans, and $\mathrm{T}_{\mathrm{L}} / \mathrm{L}$ which were $+0.003,+0.010$, and +0.004 units a year respectively. We consider that the mean difference in age of 1.2 years would not bias any conclusions we might draw.

Two way analysis of variance within cases and controls and between areas showed highly significant differences between area mean values for 16:1 trans $(\mathrm{F}=6 \cdot 3, \mathrm{p}<0.01)$, for $18: 1$ trans $(\mathrm{F}=17: 7 \mathrm{p}<$ $0.001)$, and for $T_{\downarrow} / L(F=5.5, p<0.01)$. There is however no evidence that case/control diferences vary between areas $(F=0.9,1.1$, and 1.0 respectively).

To pool the results, therefore, we used the method of weighted means of Pearce, ${ }^{10}$ and table 2 shows the differences in mean values for cases minus controls for 16:1 trans, 18:1 trans, their sum $T_{L}$, for $T_{H}$, and for various ratios. This reaffirms our previous analysis $^{3}$ that the differences between cases and controls are significant for $T_{L}$ but not for $T_{H}$.

\section{Discussion}

CASE CONTROL LEVELS OF LOWER TRANS ACIDS

The weighted mean value of $T_{H}$, as expected, is virtually identical with that of the controls. In contrast, mean percentages of $16: 1$ trans and 18:1 trans are higher for the case specimens by amounts

Table 1 Area mean values of $L, 18: 1$ trans, 16:1 trans, $T_{L}$, and $T_{L} / L, 136$ cases $(C), 95$ controls (K)

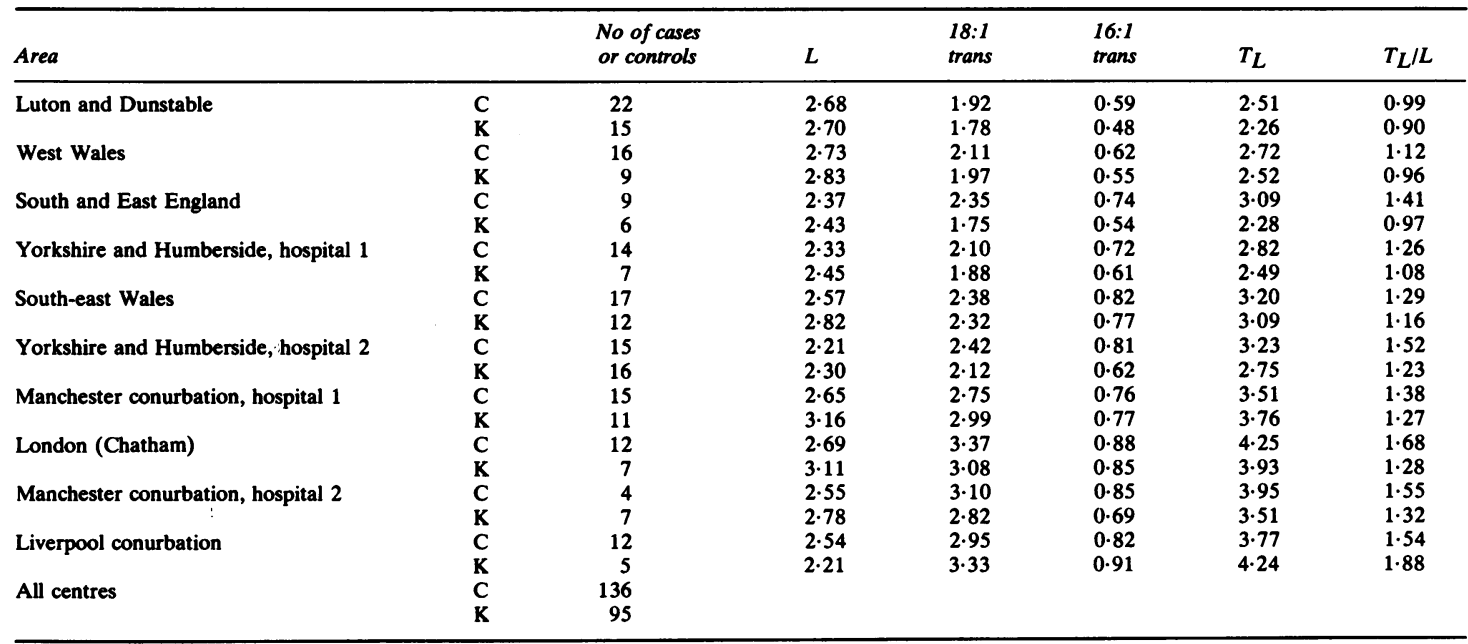

Table 2 Overall adipose tissue composition: weighted differences cases minus controls

\begin{tabular}{|c|c|c|c|c|c|}
\hline \multirow[b]{2}{*}{$\begin{array}{l}\text { Component } \\
\text { trans acids }\end{array}$} & \multirow[b]{2}{*}{$\%$} & \multicolumn{3}{|l|}{ Differences } & \multirow[b]{2}{*}{$p$} \\
\hline & & $\begin{array}{l}\text { Mean } \\
\text { differences }\end{array}$ & $\begin{array}{l}\text { Standard } \\
\text { errors }\end{array}$ & Student's $t$ & \\
\hline $\begin{array}{l}16: 1 \text { trans } \\
18: 1 \text { trans } \\
T_{L}{ }^{*} \\
\text { Total trans acids }(\mathrm{T}) \dagger \\
T_{H^{\ddagger}} \\
T_{L} / \mathrm{L} \\
16: 1 \text { trans } / \mathrm{L}\end{array}$ & $\begin{array}{l}0 \cdot 708 \\
2 \cdot 397 \\
3 \cdot 105 \\
5 \cdot 327 \\
2 \cdot 222 \\
1 \cdot 259 \\
0 \cdot 290\end{array}$ & $\begin{array}{l}0 \cdot 0820 \\
0 \cdot 1308 \\
0 \cdot 2128 \\
0 \cdot 2264 \\
0 \cdot 0136 \\
0 \cdot 1670 \\
0 \cdot 0532\end{array}$ & $\begin{array}{l}0.0279 \\
0.0746 \\
0.0952 \\
0.2185 \\
0.1551 \\
0.0578 \\
0.0159\end{array}$ & $\begin{array}{l}2 \cdot 94 \\
1 \cdot 75 \\
2 \cdot 23 \\
1 \cdot 04 \\
0.09 \\
2 \cdot 89 \\
3 \cdot 35\end{array}$ & $\begin{array}{l}<0.005 \\
\text { NS } \\
\sim 0.025 \\
\text { NS } \\
\text { NS } \\
<0.005 \\
<0.001\end{array}$ \\
\hline
\end{tabular}

- $T_{L}=16: 1$ trans plus 18:1 trans.

tTaken from reference 1 .

$\neq T_{\mathbf{H}}=\mathbf{T}-\mathbf{T}_{\mathbf{L}}$. 
$0.08 \%$ and $0.13 \%$ respectively, the difference being significant at $\mathrm{p}<0.005$ for the former but only at the $8 \%$ level for the latter acid. For total lower trans acids $\mathrm{T}_{\mathrm{L}}$, the case mean is higher by an amount $0.21 \%$ at significance level $p \sim 0.025$.

An obvious interpretation of the results is that whereas there is no evidence that higher trans acids are harmful, risk attaches to lower trans acids (particularly to 16:1 trans) purely in virtue of these having a trans configuration irrespective of other structural considerations. Whereas this is undoubtedly a possibility, it ignores the fact that trans acids from differing sources of fat are not identical in structure.

Commercial hydrogenation of vegetable oils $\mathbf{s}^{11}$ gives rise not only to trans double bonds dispersed widely along the carbon chain, but also to a variety of positional cis isomers. According to Carpenter et al ${ }^{12}$ about $30 \%$ of the cis 18:1 remaining consists of isomers with their (cis) bonds in a variety of positions other than the w9 position of natural oleic acid. Bearing in mind that 18:1 is the major acid in most margarines and cooking oils/fats, this $30 \%$ forms a substantial part of the whole product.

Hydrogenated marine oils also contain 18:1 and 16:1 positional isomers ${ }^{13}{ }^{14}$-possibly in amount greater than in hydrogenated vegetable oil.

In ruminant-animal fat the trans double bonds are more centrally placed, and randomisation of the cis bonds is far less pronounced, ${ }^{15}$ over $95 \%$ of the monoenoic content remaining in "natural" position.

Necessarily, therefore, the 16:1/18:1 trans acid content of hydrogenated fats is positively correlated with amounts of positional cis isomers. In ruminant-animal fats amounts of the latter will be very small in comparison.

Although we have no experimental evidence at present, it also seems likely from consideration of the manufacturing process that amounts of $T_{L}$ from margarine to margarine will correlate positively with amounts of artificial antioxidants and possibly even with residual Ni catalyst. Addition of such additives to butters sold as such is prohibited. We prefer therefore to use 16:1 trans and 18:1 trans acids as "markers" indicative of certain types of fat without necessarily implicating any particular component acid or additive. In this respect it should be remembered that whereas 16:1 trans is highly characteristic of hydrogenated marine oils, ${ }^{3}$ only about $40 \%$ of $18: 1$ trans is contributed by hydrogenated fats, the remainder coming from ruminant-animal fat. In consequence amounts of positional isomers per unit amount of 16:1 trans will be considerably greater than amounts per unit amount 18:1 trans. Using lower trans acids as markers, therefore, it is not surprising that whereas the 16:1 trans content of the case specimens is significantly higher than for controls, mean 18:1 trans levels are more variable and the case minus control difference is not significant.

RATIO OF LOWER TRANS ACIDS TO L AS A MEASURE OF RELATIVITY OF HYDROGENATED FATS TO RUMINANT-ANIMAL FAT

For zero intake of hydrogenated fats, the expected value of $T_{\nu} / L$ for otherwise average United Kingdom dietary fat is ca $\mathbf{0 \cdot 6}$. (This figure is somewhat lower than the previous figure ${ }^{3}$ for $\mathrm{T} / \mathrm{L}$, since we have found that in butter fat about $20 \%$ of the total trans content resides within the "higher acid" content.) Inclusion of hydrogenated marine or vegetable oils-of $T_{L} / L$ values about eight and 60 respectively-will result in sharp increase in this ratio. In agreement with this estimate we have found that of the 231 specimens analysed, only six have values of $T_{L} / L$ between 0.5 and 0.6 , the rest falling between 0.7 and the highest value 2.9 . The weighted mean value of $T_{L} / L$ for the cases is 1.342 and that for the controls is $1 \cdot 175$, the difference being significant at $p<0 \cdot 005$.

On the reasonable assumption that an amount of butter is replaced by margarine, but consumption of pig/poultry fat remains constant, this difference implies that the cases on average consume about $30 \%$ more (average-type) margarine and $10 \%$ less butter fat than the control group.

In respect of ratio $16: 1$ trans/L the difference between case and control specimens is significant at $p<0.001$, and it might be inferred that hydrogenated marine oil carries a higher risk than hydrogenated vegetable oil containing much 18:1 trans but no $16: 1$ trans. Whereas this is undoubtedly a possibility, however, precise amounts of positional isomers and additives associated with these two types of hydrogenated fat are at present unknown. Furthermore, since, in fact, 16:1 trans and 18:1 trans are strongly correlated, we beleive that it would be premature to apportion risk to the one more than to the other.

For the United Kingdom detailed knowledge relating to relative amounts of the various fatty components making up the total intake of dietary fat is available, and it is possible to calculate the composition of the average fatty diet in England and Wales. From such a calculation it has been shown ${ }^{1}$ that the fatty-acid composition of such diet agrees remarkably well (subject only to body desaturation of $16: 0$ to $16: 1$ cis and $18: 0$ to $18: 1$ cis) with the average composition of 95 control samples of depot fat drawn widely from that population. Agreement extends to such minor compounds as odd-number and branched-chain acids (L) and trans acids. Furthermore, it was shown ${ }^{2}$ that depot fat regional 
variations in the ratio trans acids/ $L$ correlate satisfactorily with known dietary variations.

On the premise, therefore, that population mean levels of lower trans and $\mathrm{L}$ acids in adipose tissue reflect dietary intakes, we conclude that the cases consumed a higher amount of hydrogenated fat ralative to ruminant-animal fat than did the controls. Put in another way-since consumption of hydrogenated fat is in general known to be negatively correlated with consumption of ruminant-animal fat ${ }^{2}$ - the cases consumed on average the higher amount of hydrogenated fat and the lower amount of ruminant-animal fat. Further, it follows that on a weight-for-weight basis, those hydrogenated fats having higher content of lower trans acids will present the greater risk and in this respect it is possible that some hydrogenated vegetable oils may well be more harmful than hydrogenated marine oils.

In addition to the observed within-area case $v$ control differences, differences in area mean values of lower trans acids are of interest (table 1). Although precise comparison is clearly not possible, highest mean values of, for instance, 16:1 trans are found in those areas of highest mortality from ischaemic heart disease - that is, in urban conurbations; lowest mean values are found in South-east England-that is, in a region of lowest mortality from ischaemic heart disease. Intermediate values appertain for Yorkshire and Humberside standard region in agreement with its intermediate SMR. ${ }^{16}$ The position of industrialised South-east Wales (compared with the more rural West Wales with its traditional very high butter consumption and quite low SMR) may be of particular interest. Although household consumption of margarine and shortenings in this area is relatively low, ${ }^{16}$ it is possible that those hydrogenated fats of high $T_{L}$ content are for some reason favoured, or that high additional amounts of hydrogenated fat are consumed by purchase and consumption of cakes, pastries, biscuits, etc, outside the private household.

Lastly, we considered the possibility that our case $v$ control differences are an artefact of case-selection in the sense that a fraction of the cases may well have suffered previous incidents of heart disease and, acting on medical advice, changed diet in favour of margarine. Medical advice in the light of current opinion, however, would surely have favoured those softer margarines described as "containing only pure vegetable oils." Such materials would have had a very high content of polyunsaturated acids and no 16:1 trans (analysis of 10 such margarines purchased over the period 1976-81 in our laboratory gave a mean percentage $18: 2$ of $31 \%$; the $18: 2$ content of butter fat is about $2 \%$ only). Our results, however, show that amounts of 16:1 trans are higher for the cases, and that levels of 18:2 are virtually identical for the case and control specimens. Again, the $\mathrm{C}_{18}$-rich hydrogenated vegetable oils are characterised by exceptionally low values of the ratio $(16: 0+$ $16: 1) /(18: 0+18: 1)$ whereas butter fat is relatively rich in $\mathrm{C}_{16}$ acids, but we have found ${ }^{2}$ that the mean value of this ratio is significantly lower $(p<0.01)$ for the control group. Indeed, it seems more likely that risk is associated with those hydrogenated materials of relatively low 18:2 content-that is, with hydrogenated marine oils and vegetable oils hardened in greater degree. Both of these types are widely used in the manufacture of cakes, pastries, and biscuits; such items have high fat content and would surely not have been favoured by the dietitian.

We thank Dr P C Elwood, director, MRC Epidemiology Unit (South Wales) for his continued encouragement and Professor H Campbell of the Welsh National School of Medicine for his.help and generous advice. We are in receipt of a grant from the Welsh Committee for Locally Organised Research.

Requests for reprints to: Leo $H$ Thomas, Department of Science, The Polytechnic of Wales, Mid-Glamorgan CF37 1DL.

\section{References}

${ }^{1}$ Thomas LH, Jones PR, Winter JA, Smith $H$. Hydrogenated oils and fats; the presence of chemically-modified fatty acids in human adipose tissue. Am J Clin Nutr 1981; 34: 877-86.

${ }^{2}$ Thomas LH, Scott RG. Ischaemic heart disease and the proportions of hydrogenated fat and ruminant-animal fat in adipose tissue at postmortem examination: a case/control study. J Epidemiol Community Health 1981; 35: 251-5.

3Thomas LH, Winter JA, Scott RG. Concentration of transunsaturated fatty acids in the adipose body tissue of decedents dying from ischaemic heart disease compared with controls. An analysis of covariance. J Epidemiol Community Health 1983; 37: 22-24.

${ }^{4}$ Supelco Inc. Methyl elaidate/methyl oleate, cis-trans isomers. Bellefonte, PA: Supelco Inc, 1975. (Bulletin No 752A.)

${ }^{5}$ Christie WW. Lipid analysis. London: Pergamon Press, 1973: 108.

- Jamieson GR. Structure determination of fatty esters by gas liquid chromatography. In: Gunstone FD, ed. Topics in lipid chemistry. Vol 1. London: Elek, 1970.

${ }^{7}$ Christie WW. Lipid analysis. London: Pergamon Press, 1973: 135.

${ }^{8}$ Christie WW. Lipid analysis. London: Pergamon Press, 1973: 50.

9 Jensen RG, Quinn JG, Carpenter DL, Sampugna J. Gas-liquid chromatographic analysis of milk fatty acids: a review. J Dairy Sci 1967; 50: 119-26. 
${ }^{10}$ Pearce SC. The estimation of treatment means by designed experiments. Applied Statistics 1974; 23: 22-5.

${ }^{11}$ Emken EA, Dutton HJ. Geometrical and positional fatty acid isomers. Champaign, Illinois: The American Oil Chemists' Society, 1979.

${ }^{12}$ Carpenter DL, Slover HT. Lipid composition of selected margarines. Journal of the American Oil Chemists' Society, 1973; 50: 372-6.

${ }^{13}$ Lambertson G, Myklestad H, Braekkan OR. Studies on monoene fatty acid isomers in hydrogenated fish oils. Journal of the American Oil Chemists' Society, 1971; 48: 389-91.
${ }^{14}$ Conacher HBS, Page BD, Chadha RK. Isomers of monoethylenic fatty acids in some partially hydrogenated marine oils. Journal of the American Oil Chemists' Society, 1972; 49: 520-3.

${ }^{15}$ Hay JD, Morrison WR. Isomeric monoenoic fatty acids in bovine milk fat. Biochim Biophys Acta 1970; 202: 237-43.

${ }^{16}$ Thomas LH. Mortality from arteriosclerotic disease and consumption of hydrogenated oils and fats. $\mathrm{Br} J$ Prev Soc Med 1975; 29: 82-90. 